\title{
A inovação como conexão para o desenvolvimento de parcerias entre universidade-empresa
}

A presente pesquisa, por meio de estudo de caso no setor agrícola, tem como objetivo analisar como ocorre a relação Universidade-Empresa (U-E) quanto ao contexto para a criação e transferência do conhecimento. Pretende-se analisar esse tipo de relação que acontece por intermédio da Estação Experimental denominada Fazenda-Escola de propriedade da Universidade Estadual de Ponta Grossa, onde está localizado um Campo Experimental Avançado sob responsabilidade da Empresa BASF S. A. A relação Universidade-Empresa tem se intensificado e, dentro desse contexto, as instituições de ensino e pesquisa podem contribuir de forma eficiente com a geração de novas tecnologias e conhecimentos, manifestando-se como uma alternativa de inovação juntamente com a iniciativa privada. Nesse sentindo, foram identificadas as formas, os fatores intervenientes e seus fatores estruturais no âmbito da criação e transferência do conhecimento em entrevistas com o pesquisador da universidade, o administrador da fazenda-escola da universidade e o responsável técnico pelo campo experimental da empresa. Optou-se, portanto, por uma pesquisa qualitativa, baseada em estudo de caso visando explorar a percepção das pessoas envolvidas sobre o fenômeno em análise. Os resultados indicam novos fatores intervenientes no processo de criação e transferência do conhecimento, considerados importantes para a gestão do processo e a relação com a empresa.

Palavras-chave: Conhecimento. Relação Universidade-Empresa. Inovação.

\section{INTRODUÇÃO}

Em virtude da busca constante pela inovação, as empresas desenvolveram seu planejamento estratégico, procurando alternativas de ações que garantissem sua competitividade no mercado. A partir dos anos 1990, o processo de planejamento estratégico começa a ser questionado e a desenhar algo mais amplo. Não é suficiente planejar, é preciso administrar de forma estratégica (FISCHMANN; CUNHA, 2003).

Contudo, no cenário atual, a importância dada à inovação tecnológica tem sido percebida como irrefutável para o aumento da competitividade no cenário nacional. Um dos argumentos que tem sido construído no meio acadêmico é que uma forma utilizada para o desenvolvimento de inovações tecnológicas, nos países que se têm destacado em inovar, é a cooperação entre a universidade e a empresa (NOVELI; SEGATTO, 2012).

O processo de cooperação Universidade e Empresa pode trazer inúmeros benefícios, tanto para os agentes envolvidos diretamente quanto para a sociedade. Dentre os benefícios dessa cooperação, destaca-

${ }^{1}$ Mestre em Gestão de Políticas Públicas pela Universidade do Vale do Itajaí - myller_3@hotmail.com

2 Prof. Doutor do Programa de Pós-Graduação em Administração da Universidade do Vale do Itajaí - claudio.goncalo@univali.br

${ }^{3}$ Mestranda em Administração pela Universidade do Vale do Itajaí - christiane.pereira2006@ig.com.br

${ }^{4}$ Doutoranda em Administração pela Universidade do Vale do Itajaí - sandrabiblio@hotmail.com 
se o ganho para a empresa em ter uma equipe altamente capacitada pesquisando a propósito de seus problemas ou de formas de melhorar seus processos, produtos, serviços; e, para a Universidade, o incentivo financeiro que possibilita a realização de pesquisas, tornando disponível à sociedade a utilização de seus resultados (SBRAGIA et al., 2006).

Desse modo, o principal papel do governo no que concerne à inovação tecnológica, portanto, é o de prover os incentivos corretos ao desenvolvimento e à difusão de ideias por parte do setor privado (ações indiretas). Mas também promover um ambiente político, econômico e institucional que estimule as empresas a investir em ciência, tecnologia, pesquisa e desenvolvimento (FONSECA, 2001).

0 tema desta pesquisa apresenta, por si só, relevância ao momento atual, na medida em que a sociedade espera que as universidades apoiem as empresas na criação do conhecimento que se consolida em inovação tecnológica para a construção de uma realidade de desenvolvimento econômico e sustentável. Essas instituições também esperam do governo políticas públicas que venham aliviar a burocracia do processo de relacionamento, bem como promover incentivos. De maneira geral, as investigações a propósito da relação Universidade-Empresa buscam analisar e identificar fatores facilitadores, motivacionais, barreiras e resultados alcançados no processo de relacionamento.

Nessa perspectiva, o presente estudo tem como objetivo analisar como ocorre a relação UniversidadeEmpresa (U-E) quanto ao contexto para a criação e transferência do conhecimento, mediante um estudo de caso no setor agrícola. Pretende-se analisar esse tipo de relação que acontece por intermédio da Estação Experimental denominada Fazenda-Escola, de propriedade da Universidade Estadual de Ponta Grossa, onde está localizado um Campo Experimental Avançado sob responsabilidade da Empresa BASF S. A.

Considerando a importância da inovação tecnológica no contexto científico e empresarial, as relações Universidades-Empresas no Brasil devem ser fortificadas a fim de que os potenciais dessas organizações sejam unificados para o desenvolvimento socioeconômico e tecnológico. Utilizando Etzowitz $(2003,2010)$ e Plonski $(1995,1999)$ como base, buscou-se estudar a relação Universidade-Empresa e outros modelos de relacionamento colaborativo, de modo que esta pesquisa orientou-se no seguinte problema: como ocorre a relação Universidade-Empresa na criação de um contexto para a criação e transferência do conhecimento no setor agrícola?

\section{FUNDAMENTAÇÃO TEÓRICA}

As palavras de Schumpeter (1961) podem ser traduzidas como previsões de um futuro que estaria por vir no qual inovações radicais podem provocar mudanças, enquanto inovações 'incrementais' preenchem o processo de mudança. Esses processos incrementais proporcionam diferenciais nas capacidades existentes nas empresas, que estão além de simplesmente desenvolver novas habilidades e conhecimentos. 0 referido processo reforça a capacidade da empresa para oferecer soluções e possibilidades (SCHUMPETER, 1961; HENDERSON; CLARK, 1990; WINTER, 2003).

0 conhecimento representa um diferencial econômico, pois, ao definir uma "economia baseada em conhecimento", remete-se aos avanços tecnológicos, gerados pelo alto volume de informaç̧ões disponíveis e acesso às inúmeras tecnologias, que permitem melhorar recursos e capacidades disponíveis nas empresas (OCDE, 2005). Os novos conhecimentos não estão dissociados dos recursos existentes na empresa, eles atuam em uma complementaridade às habilidades existentes, sendo identificadas a partir das necessidades ambientais (KOGUT; ZANDER, 1992).

A partir de uma nova visão estratégica, por parte das empresas em reconhecer a importância do conhecimento, inúmeros investimentos passam a ser realizados com objetivo de ampliar as capacidades produtivas e tecnológicas existentes nas empresas que permitam sustentá-las em um novo ritmo imposto pelo mercado (OCDE, 2005).

Nesse sentido, os investimentos consentem que áreas de pesquisa e desenvolvimento estejam efetivamente focadas nas novas oportunidades criadas aos recursos humanos por meio de capacitação, treinamento, educação e parcerias, melhorando, assim, sua capacidade técnica para criar condições que conduzam aos caminhos da inovação e que provoquem mudanças econômicas efetivas (OCDE, 2005).

\subsection{Inovação e conhecimento: uma construção dinâmica}

Identifica-se inovação como a implementação de decisões deliberadas feitas para melhorar o desempenho da empresa, explorando oportunidades de mercado e respondendo aos desafios do ambiente de negócios, incluindo no processo ferramentas, materiais, habilidades e conhecimento adquirido. 
Inovações são objetos que podem ser limitados e descritos por mudanças demarcadas em características de desempenho ou a criação de novas características de desempenho (HAUKNES, 1998).

Nesse sentido, a inovação engloba uma imensa combinação de fatores que permitem sua ampliação nas empresas; dentre esses fatores, estão a disseminação da cultura da inovação no âmbito social, ampliando incentivos às empresas que contribuem e "respiram" inovação, por meio de seus serviços, produtos, processos, investimentos internos e constantes em pesquisa e desenvolvimento (P\&D), além da contratação de profissionais especializados e desenvolvimento de parcerias que ampliem eficiências e aspectos competitivos das empresas (IBGE, 2011).

Abordando-se o conhecimento relacionado à transferência de melhores práticas dentro da empresa, os profissionais entendem como a replicação de uma prática interna que é realizada em uma dada localidade da organização de forma superior às demais práticas utilizadas pela empresa ou conhecidas fora dela (SZULANSKI, 1996).

A palavra "prática" refere-se à rotina organizacional de utilização do conhecimento e, em geral, tem um componente tácito, inerente às habilidades individuais e aos arranjos sociais. A palavra "transferência" é usada para enfatizar que o movimento do conhecimento é uma experiência distinta e que depende das características do contexto e de todos os envolvidos: fonte e receptor. A transferência de conhecimento pode ser compreendida como uma replicação de rotinas organizacionais (SZULANSKI, 1996).

Na compreensão de Szulanski (1996), identificam-se estágios no processo de transferência de conhecimento, e, na proporção em que isso acontece dentro das empresas, segue um processo no qual seus fatores não só aparecem em maior ou menor grau, como também em uma determinada ordem de acontecimento. 0 autor identifica quatro estágios, na seguinte ordem: iniciação, implementação, ramp-up e integração.

A iniciação compreende todos os eventos que levam à decisão de transferir conhecimento. De acordo com o autor, inicia com a identificação de uma necessidade e do conhecimento necessário para satisfazê-la, possivelmente existente na organização, mas que ainda não foram ligados. Uma vez que a necessidade e uma solução potencial foram identificadas, sua adequação e possibilidade de transferência devem ser analisadas.

A fase de implementação, segundo Szulanski (1996), inicia com a decisão de transferir o conhecimento. As partes trocam recursos (conhecimento), e adaptações são feitas para atender às necessidades do receptor, antecipadas na fase anterior, para prevenir problemas ocorridos em transferências passadas ou para tornar o processo mais suave. Atividades relacionadas a esse estágio desaparecem ou diminuem muito quando o receptor começa a utilizar o conhecimento recebido.

O ramp-up pode ser entendido como o período de adaptação do receptor, tendo início quando ele utiliza o conhecimento recebido, cujo foco das atenções estará na identificação e solução de problemas inesperados que prejudicam sua habilidade de atender às expectativas de desempenho ou excedê-las. É comum que o receptor seja menos eficiente no início, mas que gradualmente melhore seu desempenho até atingir o nível esperado, representando esse estágio um período curto para corrigir problemas inesperados (SZULANSKI, 1996).

A integração começa quando o receptor atingiu o nível esperado de desempenho na utilização do conhecimento recebido, transformando o uso desse novo conhecimento em parte da rotina. Com o passar do tempo, o receptor cria uma história de uso desse conhecimento, com significados, comportamentos, ações e atores familiares ao seu meio. Essa nova rotina facilita a coordenação de atividades, tornando os novos comportamentos estáveis, previsíveis e fáceis de entender. Essas novas práticas tornam-se institucionalizadas, fazendo parte dos objetivos e da realidade da organização (SZULANSKI, 1996).

Ainda dentro do contexto, Szulanski $(1996,2000)$ indica quatro conjuntos de fatores que influenciam a dificuldade (stickiness) no processo de transferência do conhecimento: características do conhecimento transmitido, em que os principais fatores são: ambiguidade e histórico de sucesso; características da origem do conhecimento: falta de motivação e confiabilidade; características do receptor do conhecimento: falta de motivação do receptor, falta de capacidade de absorção e retenção; e características do contexto da transferência: barreiras organizacionais e relações difíceis.

Na busca pela eficiência e pelo aumento da competitividade, as empresas visualizam oportunidades que podem ser encontradas no ambiente externo e estão baseadas no conjunto de relações construídas por tais empresas. As parcerias podem envolver altos investimentos, especialmente quando se trata de pesquisas que exigem da empresa análises de estudos longitudinais fazendo com que essa parceria seja de curto, médio e até de longo prazo (PLONSKI, 1995, 1999).

Nessa direção, os trabalhos realizados em conjunto com a pesquisa vão sendo delineados entre a empresa e a universidade, adquirindo maturidade ao longo do tempo, tanto nos relacionamentos quanto em pesquisas, e o que torna a parceria eficaz é a descoberta dos interesses comuns em prol da busca pelos 
objetivos estratégicos de cada participante (PLONSKI, 1995, 1999).

Quando falado anteriormente em investimentos em pesquisa e desenvolvimento, é preciso compreender que a realidade das empresas nem sempre é favorável ao momento em que os investimentos são necessários. Dessa forma, sua capacidade em construir relacionamentos estratégicos que realmente atuem na complementaridade dos recursos existentes na empresa pode caracterizar a diferença entre a manutenção e a perda de mercado (DYER; KALE, 2007).

A relação entre atores propicia resultados positivos para o processo de inovação, oferecendo benefícios que podem firmar ainda mais a parceria, sendo estes: conhecimento compartilhado, complementaridade de competências e escalas em projetos de P\&D, que podem ampliar significativamente no que tange ao conhecimento e à vantagem de uma empresa perante os seus concorrentes (BALESTRIN; VERSCHOORE, 2008).

Nessa linha de raciocínio, tendo em vista os aprimoramentos tecnológicos e maiores fluxos de informação, o conhecimento é cada vez mais percebido como um condutor central do crescimento econômico e da inovação. 0 conhecimento e a tecnologia tornaram-se mais complexos, aumentando a importância das interações entre organizações como uma forma de adquirir conhecimento especializado. Assim sendo, a inovação pode melhorar o desempenho da empresa, aumentando sua capacidade de inovar, proporcionando melhoramentos nos processos de produção, permitindo o desenvolvimento de produtos e novas práticas organizacionais, além de aperfeiçoar a capacidade empresarial de adquirir e criar novos conhecimentos (ALVARENGA NETO, 2004; OCDE, 2005).

\subsection{A relação Universidade-Empresa}

As inovações baseadas em conhecimento que surgem ao meio de qualquer ciência possuem o mais longo período de espera de todas as inovações. Existe, primeiramente, um longo espaço de tempo entre o aparecimento do novo conhecimento e este se tornar aplicável à tecnologia. E, depois, há outro longo espaço de tempo antes que a nova tecnologia transforme-se em produtos, processos ou serviços para o mercado (DRUCKER, 1989).

As universidades começaram a valorizar as pesquisas inicialmente na Alemanha a partir do século XIX; posteriormente, grandes universidades dos Estados Unidos passaram a adotar o modelo. No Brasil, esse processo começou a ganhar força a partir dos anos 1950, com objetivo de proteger o mercado; sendo assim, foram criados institutos voltados ao desenvolvimento científico e tecnológico. Outro ponto importante foram os investimentos financeiros que passaram a ser realizados e serviram de base para que, nas décadas seguintes, as atividades de pesquisa e desenvolvimento fossem efetivamente reconhecidas (GONÇALO; ZANLUCHI, 2011).

Assim, a Universidade sempre teve como inseparável a pesquisa e o ensino, a procura da verdade e a formação das novas gerações para essa busca perene, passando, de geração em geração, a chama que aquece e ilumina as sociedades (MENESES, 2000). A pesquisa precede o ensino; o setor produtivo precisa hoje de pequenos inventores, de espírito curioso e pensamento livre, que sejam capazes de lidar diariamente com situações novas e desafiadoras. 0 que não é fácil, mas bastante estimulante tentar (LUCCHESSI, 2002).

Esses fatores foram de grande relevância para o processo de inovação dentro do ambiente empresarial, que passou a ser percebido como fonte de sustentabilidade e competitividade, contribuindo, assim, para o desenvolvimento de estruturas de pesquisas científicas e tecnológicas, em que as parcerias entre empresas e universidades passam a ser fortalecidas. Considerando o conhecimento latente do ambiente acadêmico e o investimento das empresas em tecnologia, essa parceria torna-se de grande relevância, sendo uma via de mão dupla para a conexão dos aspectos teórico-prático, contribuindo, desse modo, para a continuidade no processo de inovação (SEGATTO, 1996).

0 modelo de interação Universidade-Empresa-Governo passou por evoluções ao longo do tempo, motivadas por ideias incrementais, como relatam Etzkowitz e Leydesdorff (2000), Almeida (2005) e Leydesdorff (2012). As interações entre os autores igualmente estão em constante evolução, exigindo, portanto, novas formas de representação geométrica do processo.

O modelo Hélice Tríplice caracteriza as relações entre o Governo, a Universidade e a Empresa, e mostra como pode ser criado um ambiente propício para a inovação, a geração e a difusão do conhecimento inerente para o desenvolvimento da sociedade (CLOSS; FERREIRA, 2010). No Brasil, a Hélice Tríplice tornou-se um "movimento" para geração de incubadoras no contexto universitário (ALMEIDA, 2005).

0 modelo Hélice Tríplice fornece um incentivo para procurar desequilíbrios entre as dimensões institucionais nos arranjos e as funções sociais desempenhadas por tais arranjos. Os atritos entre as duas camadas (baseadas no conhecimento das expectativas e interesses institucionais) e entre os três domínios (economia, ciência e política) fornecem uma riqueza de oportunidades para resolver quebra-cabeças e 
inovação (LEYDESDORFF, 2012).

Destacando as configurações da Hélice Tríplice, apresenta-se o modelo estático, no qual o governo engloba a academia e a indústria, direcionando as relações entre os autores. Dessa forma, a inovação tem um caráter normativo, fruto das diretrizes e autoridades do governo e não da dinâmica e da relação entre a universidade e a indústria (ETZKOWITZ; LEYDESDORFF, 2000; ALMEIDA, 2005; LEYDESDORFF, 2012). O modelo laissez-faire, no qual se observa uma separação das três esferas e linhas pontilhadas, representa as relações entre os autores, atenuando, dessa maneira, o papel do governo (ETZKOWITZ; LEYDESDORFF, 2000; LEYDESDORFF, 2012).

Olhando as organizações, essas existem para entender as necessidades humanas por intermédio de seus produtos e serviços. A expectativa de sobrevivência da organização, em uma economia de mercado livre, é proporcional à sua capacidade de desenvolver novos produtos. Nesse sentido, o fator com maior evidência sobre influências no gerenciamento do processo de desenvolvimento de produtos é o grau de inovação do projeto (MATTOS; GUIMARÃES, 2005).

Relativamente ao grau de inovação da linha atual de produtos da empresa, apresenta-se a seguinte classificação: pesquisa e desenvolvimento avançados: processos de desenvolvimento, cujo objetivo é criar o conhecimento (know-how) para futuros projetos; plataformas ou nova geração: processos de desenvolvimento que incorporam inovações significativas no produto e/ou processo; e derivados: processos de desenvolvimento que criam um novo produto dentro de uma família (MATTOS; GUIMARÃES, 2005).

Por fim, a inovação tecnológica é definida pela introdução no mercado de um produto (bem ou serviço) tecnologicamente novo ou substancialmente aprimorado, ou pela introdução de um processo produtivo tecnologicamente aprimorado ou novo. "A inovação tecnológica pode resultar de novos desenvolvimentos tecnológicos, de novas combinações de tecnologias existentes ou da utilização de outros conhecimentos adquiridos pela empresa" (RESENDE; TAFNER, 2005, p. 45).

\section{PROCEDIMENTOS METODOLÓGICOS}

Tomando por base o objetivo do artigo, optou-se pela utilização de um estudo que permitisse explorar a percepção dos entrevistados quanto à relação Universidade-Empresa. A pesquisa teve sua abordagem qualitativa, sendo a forma mais adequada para conhecer a natureza de um fenômeno social. 0 campo empírico investigado foi a Fazenda-Escola, da Universidade Estadual de Ponta Grossa (UEPG).

Quanto ao método de pesquisa, elegeu-se o estudo de caso descritivo em virtude de seu contexto peculiar específico de pesquisa. Segundo Yin (2001), o estudo de caso é uma inquirição empírica que investiga um fenômeno contemporâneo dentro de um contexto de vida real, quando a fronteira entre o fenômeno e o contexto não é claramente evidente e onde múltiplas fontes de evidência são utilizadas.

Nesse contexto, analisou-se a relação da universidade com a empresa Basf S.A., a qual iniciou em 1994, desenvolvendo uma trajetória de sucesso até os dias de hoje. Com base na teoria estudada, visando compreender a relação Universidade-Empresa no âmbito da criação e transferência do conhecimento organizacional, foram definidas as técnicas de pesquisa, utilizando-se roteiros de entrevista semiestruturados e análise documental, juntamente com publicações a respeito do tema investigado.

Dessa forma, os temas estão agrupados em três dimensões: fatores estruturais, criação e transferência do conhecimento organizacional, e fatores que interferem na relação Universidade-Empresa. Os fatores estruturais procuram identificar quais os mecanismos de gestão utilizados pela empresa e pela universidade relativamente à formalização e implementação do Campo Experimental Avançado na Fazenda-Escola. Por causa da peculiaridade dessa relação, a localização interna procura entender qual é a vantagem para a universidade e para a empresa em desenvolver um Campo Experimental dentro de uma Estação Experimental da universidade (Apêndice A).

Analisando a dimensão da criação e transferência do conhecimento organizacional, procura-se identificar as categorias citadas na teoria sobre a criação e transferência do conhecimento organizacional, adotadas entre a empresa e a universidade. Tais dimensões possuem características diferenciadas quanto ao tempo de duração e intensidade dos contatos.

No que concerne aos fatores que interferem no processo de relação Universidade-Empresa, os pesquisados foram questionados sobre quais as barreiras que limitam ou inviabilizam uma relação Universidade-Empresa mais intensa, e o que, porventura, pode facilitar tal relação na criação e transferência do conhecimento organizacional.

Foram entrevistados, entre os meses de janeiro e fevereiro de 2013, o pesquisador da universidade, sendo este professor e consultor técnico desde 1986, com formação em nível de Doutorado; o administrador da 
Fazenda-Escola da Universidade, professor desde 1991, com formação em nível de Doutorado, atuando como administrador da Fazenda-Escola desde 2006; e o responsável técnico do Campo Experimental Avançado da empresa Basf the Chemical Company, que está há dezesseis anos atuando na divisão de desenvolvimento de produtos da empresa, com formação em nível de graduação. As entrevistas foram gravadas com duração entre $22 \mathrm{~min}$ e $1 \mathrm{~h} 20 \mathrm{~min}$, sendo realizadas em Ponta Grossa, tendo em vista a localização da universidade e da empresa.

Após a transcrição das entrevistas, os resultados foram descritos e analisados no seu conteúdo, considerando os elementos de análise previamente definidos para a investigação. A primeira dimensão a ser analisada são os fatores estruturais, que estão divididos em duas categorias: mecanismos de gestão e localização interna. A segunda dimensão analisa a criação e transferência do conhecimento, que está dividida em duas categorias: a criação e a transferência. Finalmente, analisam-se os fatores intervenientes, que estão decompostos em duas categorias: barreiras e facilitadores.

\section{DESCRIÇÃO E ANÁLISE DOS RESULTADOS}

As evidências levantadas no estudo de caso permitem demonstrar a importância de se firmar parcerias estratégicas que construam efetivo resultado para ambas as partes. Nem sempre um projeto idealizado apresenta resultados efetivos em uma parceria Universidade-Empresa, por mais que as partes tenham interesse. É preciso conhecer os objetivos estratégicos que foram propostos na construção da parceria.

Para evidenciar se o processo de inovação entre Universidade-Empresa (U-E) foi o grande motivador da parceria, baseado também no aprofundamento da fundamentação teórica, a categoria analisada foi a transferência do conhecimento, empregando etapas descritas por Szulanski (1996), no processo de transferência, como iniciação, implementação, adaptação e integração, a fim de demonstrar como ocorre esse fenômeno dentro do campo empírico, baseando-se em três perspectivas.

\subsection{Fatores estruturais}

Acerca das três perspectivas identificadas, os fatores organizacionais estão divididos em duas categorias. A primeira delas compreende os mecanismos de gestão cujo objetivo é identificar práticas voltadas à implementação do campo experimental; a segunda, a localização interna, tem o intuito de entender qual é a vantagem e possíveis desvantagens para a universidade e para a empresa, em desenvolver um campo experimental dentro de uma estação experimental da universidade.

Percebe-se, na fala do pesquisador da UEPG, que, no que diz respeito ao estímulo das relações U-E, o estímulo está sendo desenvolvido lentamente ao longo dos anos. Acrescenta o pesquisador, ainda, que a criação da relação U-E normalmente era uma atividade individual, ou seja, dependia de cada pesquisador. Ressalta a existência do preconceito, característica recorrente na relação U-E identificada como umas das barreiras dessa relação (ZANLUCHI, 2008; SEGATTO, 1996).

Em consonância à fala do pesquisador, o administrador da fazenda-escola indica a existência de uma política para estimular a criação da comunicação entre empresas e universidade. Entende-se que essa política é nova na instituição; porém, os benefícios da relação para todos os atores começam a ficar mais claros como ressaltou o administrador.

No entendimento da Basf (2014), o surgimento de relações com a universidade aparece decorrente de uma necessidade. Tal necessidade é descrita como sendo da agricultura, sabendo que a inovação da empresa depende de iniciativas em que as necessidades são a mola impulsora do processo inovador para a ótica da empresa. Esse entendimento é citado por Mattos e Guimarães (2005), ao explicar que as organizações existem com a finalidade de atender às necessidades humanas e, também, à expectativa de sobrevivência da organização.

Com a troca de informação com professores e acadêmicos, a empresa consegue moldar alguns dos fatores econômicos descritos por Betz et al. (1997): mão de obra, administração, produtos, recursos e tecnologias. Hoje as práticas administrativas estão mais atentas aos efeitos de longo prazo das velozes mudanças tecnológicas em produtos, processos e serviços, que se baseiam em uma combinação de tecnologia.

Analisando-se os processos informais, na interpretação do pesquisador, há práticas que acontecem além do contrato firmado, são relações de cumplicidade, nas quais a prestatividade da empresa em relação à universidade é benéfica. Tratando-se de iniciativa privada, a destinação de recursos materiais e financeiros acaba sendo mais objetiva no que se refere ao serviço público, pois este depende de direcionamentos orçamentários, licitações, dentre outros procedimentos burocráticos, utilizados pelo aparato do Estado. 
Partindo para um enfoque de gestão, no qual foram baseadas as informações do administrador da fazenda-escola, constata-se que não existem processos informais dentro da relação Universidade-Empresa, possuindo as universidades direitos e deveres; além disso, as empresas igualmente possuem direitos e deveres. Partindo disso, a realização de uma parceria técnico-científica, com uma universidade pública, acaba passando por barreiras legais inerentes à construção e transferência de tecnologia (PORTO, 2000).

Identificando-se as contribuições relatadas pela Basf The Chemical Company, tudo precisa ser muito transparente para que não ocorram prejuízos às partes interessadas. Sob essa perspectiva, a empresa ainda reconhece que há uma informalidade na relação Universidade-Empresa a qual beneficia ambas as partes.

Para a universidade, aqui representada pela fazenda-escola, a maioria das parcerias técnico-científicas servem para realizar as vitrines tecnológicas, sendo essas uma forma de a empresa apresentar seu portfólio de produtos à sociedade juntamente com um especialista da área. Dessa forma, a credibilidade da empresa é construída pelo profissional da universidade, em virtude de seu conhecimento relativamente ao foco do problema (GRYNSZPAN, 1999; MENESES, 2000; LUCCHESSI, 2002; MATTOS; GUIMARÃES, 2005).

Chegando às análises das possíveis vantagens sob a percepção do pesquisador, ele relata que o fato de ter as empresas próximas da universidade proporciona um espaço em que a universidade pode vender serviços. Esses serviços são classificados pelo pesquisador em primeiro plano - tecnologia; segundo - os estudantes que se formam poderão ser absorvidos e contratados por essas empresas; terceiro - a universidade obtém recursos financeiros e materiais.

Dentro da relação UEPG e Basf The Chemical Company, observa-se que é saudável para a universidade. O entrevistado relata que possuem projetos com a Basf na Alemanha e, com base nesses projetos, houve a necessidade de construir uma estufa na fazenda-escola, sendo a estufa utilizada no projeto de pesquisa.

Dessa forma, quando houver a conclusão, ficará para uso da universidade; porém, sempre com prioridade para aquele que conseguiu a benfeitoria. 0 mencionado projeto teve um caráter de inovação, pois houve um avanço tecnológico; isso aconteceu porque a universidade é um ambiente de inovação em potencial, além da incorporação de novos mecanismos de ensino e pesquisa.

\subsection{A transferência de conhecimento como geradora de inovação}

A criação do conhecimento organizacional procura identificar o compartilhamento de conhecimento, criação de conceitos, justificativa de conceitos, construção de um arquétipo e difusão interativa do conhecimento, sendo essas categorias adotadas sob três perspectivas.

No que tange ao processo de criação do conhecimento organizacional, o pesquisador relata que o compartilhamento de experiências pessoais não acontece pelo fato de muitos projetos de pesquisa terem seus dados sigilosos. Uma forma de compartilhar experiências pessoais utilizadas eram as vitrines tecnológicas, que hoje não existem mais. Atualmente, o grupo de pesquisa está trabalhando em um projeto para tentar patentear algo por intermédio do escritório de inovação, isso demonstra que a primeira fase do processo de criação do conhecimento organizacional, o compartilhamento do conhecimento tácito, é limitada em virtude de as informações serem sigilosas (NONAKA, 1991; NONAKA; TAKEUCHI, 1997; SILVA, 2004).

Analisando o próximo ator participante do processo de relação Universidade-Empresa, o administrador da fazenda-escola relata o hábito de compartilhar experiências pessoais como na área do campo demonstrativo experimental, sendo realizados diversos experimentos cujas informações são compartilhadas com todos na fazenda-escola.

No contexto da Basf The Chemical Company, aproveita-se o horário de almoço para compartilhar informações rotineiras das atividades profissionais, existem reuniões que podem ser semanais, quinzenais ou a cada dois meses para fazer um diálogo específico com cada área de atuação. Contudo, o entrevistado relata que, na área de pesquisa, esse diálogo é constante sobre diversos assuntos voltados às experiências pessoais e a respeito de informações que possam ajudar as atividades profissionais em si.

Na compreensão da segunda fase do processo de criação, após possuir o conhecimento tácito compartilhado, ele é convertido em conhecimento explícito na espécie de um novo conceito, sendo esse processo idêntico à externalização, um tipo de conversão do conhecimento. Na terceira fase do processo de criação do conhecimento organizacional, quando há o surgimento de um novo conceito, é necessário que seja justificado; a organização, então, determina se compensa perseguir o novo conceito ou não (NONAKA, 1991; NONAKA; TAKEUCHI, 1997; SILVA, 2004).

A atribuição da organização no processo de criação do conhecimento é prover um contexto apropriado para a facilitação das atividades em equipe e para criação e retenção de conhecimento em nível individual e organizacional (SILVA, 2004). De acordo com Gonçalo (2005), a empresa valoriza ações que geram a aquisição e criação do conhecimento a partir do exercício da atividade; com isso, há igualmente o interesse 
em utilizá-lo em diferentes projetos. Entretanto, a pressão por resultados específicos para a produção sob encomenda acaba recebendo todas as prioridades.

$\mathrm{Na}$ quarta fase do processo de criação do conhecimento, quando algo tangível ou concreto pode ser criado, o pesquisador esclarece que, a partir da criação do escritório de inovação, a universidade acordou para o processo de patentes.

Sobre a busca pela inovação tecnológica, a inovação possui duas etapas, sendo a primeira composta pela ideia ou invenção; a segunda etapa consiste na comercialização. Concluindo, a ideia ou invenção são relacionadas ao processo de pesquisa e desenvolvimento, e a comercialização é voltada a temas como marketing de novos produtos ou processos (MATTOS; GUIMARÃES, 2005; RESENDE; TAFNER, 2005; MOREIRA; QUEIROZ, 2007).

Quando a inovação surge na universidade, seu tempo para adquirir a comercialização acontece em longo prazo e também depende das empresas; já, quando a inovação em sua primeira etapa surge na empresa, a comercialização ou o elo de agregação do valor acontece quando entra em linha de produção, assim confirmando que a inovação tecnológica ocorre na empresa (BETZ et al., 1997; CHAIMOVICH, 1999).

Chegando à última fase do processo de criação do conhecimento, quando acontece a difusão interativa do conhecimento, sob a ótica dos atores, o pesquisador explica que novos conhecimentos podem surgir de estímulos aos professores e pesquisadores, iniciativas louváveis do escritório de inovação na divulgação dos projetos realizados pela universidade, além da iniciativa de divulgação dos grupos de pesquisa em locais onde as empresas estarão buscando informações.

Aproximando com a fundamentação teórica, a capacidade tecnológica é definida como a capacidade de criar vantagens diferenciadas num ramo de negócio específico, é criada por meio das atividades geradas e difusoras de conhecimento. Organizações de base tecnológica que competem entre si facilitam o primeiro elo desencadeador de uma hipotética cadeia linear de inovação; assim sendo, a universidade torna-se um agente privilegiado desse entorno para a promoção da competitividade das empresas de base tecnológica (NONAKA, 1991; LEONARD-BARTON, 1998; DAGNINO, 2004).

A segunda categoria a ser analisada é a transferência do conhecimento, como iniciação, implementação, adaptação e integração, para demonstrar como ocorre esse fenômeno dentro do campo empírico, baseandose em três perspectivas.

Entre suas atividades, o pesquisador compreende que a seleção do conhecimento que será transferido é definida no momento de construção do projeto, quando é descrito se o projeto tem uma parte financiada pela empresa e outra parte pela universidade, construindo uma relação pesquisador-Universidade-Empresa, por isso a tomada de decisão precisa ser em conjunto.

Partindo do entendimento do pesquisador sobre a fase de implementação do conhecimento transferido, descreve ele que, teoricamente, a universidade e o pesquisador acompanham esse processo para que seja possível a realização das prováveis adaptações, tudo conforme o projeto firmado entre a universidade, empresa e o pesquisador.

Entrando no segundo estágio de transferência de conhecimento, a implementação compreende seu início no momento da decisão em transferi-lo. Neste estágio, são feitas adaptações para atender às necessidades do receptor e para prevenir problemas ocorridos em transferências passadas, buscando tornar o processo mais suave. A intensidade das ações aumenta e diminui conforme o receptor utiliza o conhecimento (SZULANSKI, 1996).

Quanto ao processo de adaptação, considerado o terceiro estágio na transferência de conhecimento, o pesquisador relata que é realizado um acompanhamento na transferência de conhecimento, sendo necessário ter um feedback tanto da universidade como da empresa, e o contato direto nesse processo é o pesquisador. Nesse sentido, o administrador da fazenda-escola ressalta que o acompanhamento é pontual, em virtude do convênio firmado entre a universidade e a empresa; a universidade trabalhou com alunos e pesquisadores, e vai desenvolver seu produto partindo desse conhecimento.

Em consonância à fala do pesquisador e do administrador da fazenda-escola, a Basf The Chemical Company relata que realiza pesquisas em conjunto com a universidade, fazendo parte da difusão tecnológica. Explica que, quando coloca um produto já formado no mercado, o feedback do pessoal de campo, pesquisador e vendedor é importante para uma melhor percepção; com isso, a participação no processo de adaptação é fundamental.

Compreendendo o último estágio de transferência de conhecimento, o pesquisador acredita que existem processos de avaliação de projetos que produzem resultados e, assim, gera um fator de estímulo a outros pesquisadores. 0 pesquisador lembra que "o que falta na universidade é o estímulo de pesquisa, não podemos perder patentes, fundo de royalties, a universidade no pode perder isso".

Identificado como integração, esse processo tem início quando o receptor atingiu o nível esperado de 
desempenho com o novo conhecimento, incrementando na rotina da organização. Dessa forma, a nova rotina criada facilita o andamento das atividades, fazendo a institucionalização dessas novas práticas e tornando parte da realidade da organização (SZULANSKI, 1996, 2000).

\subsection{Fatores intervenientes}

O administrador da fazenda-escola relata que a universidade representa uma parte do estado do Paraná; ambas, tanto a universidade quanto a empresa, possuem direitos e deveres que devem ser cumpridos, pois é uma relação entre órgão público e iniciativa privada, não abrindo espaço para um "jeitinho", sendo extremamente necessário o cumprimento da lei. Em relação à Basf The Chemical Company, esclarece que as barreiras são de cunho pessoal, dificuldades de relacionamento e barreiras de interesses em que ambas as organizações defendem somente os seus interesses.

Para ultrapassar as barreiras citadas, é preciso criar uma nova imagem das empresas para os professores e pesquisadores da universidade; é imprescindível dar sentido a todo conhecimento desenvolvido na universidade, alinhando com o conceito de universidade empreendedora e a criação de visão estratégica, visando transformar o conhecimento gerado pela universidade em valor social e econômico (ETZKOWITZ, 2003; AUDY; MOROSINI, 2006).

Outra forma de contribuição é a busca de possíveis desequilíbrios dentro das dimensões institucionais e as funções sociais desempenhadas pelas organizações envolvidas. 0 modelo hélice tríplice, que caracteriza as relações entre a universidade, empresa e governo, atua em relações híbridas devido às mudanças relacionadas à globalização, aos limites do governo no atendimento da população, liberação dos mercados nacionais e ao crescimento dos mercados de capitais. Consequentemente, acarreta processos de abertura de capitais das empresas, e o envolvimento torna-se equilibrado dentro de três domínios (economia, ciência e política). Dessa maneira, gerará uma riqueza de oportunidades para resolver o desafio da inovação, contribuindo para o desenvolvimento da sociedade (ETZKOWITZ, 2010; GONÇALO; ZANLUCHI, 2011).

Relatando os fatores facilitadores da relação Universidade-Empresa, o pesquisador posiciona-se descrevendo as formas de contato, realizando o marketing do grupo de pesquisa para que estejam em evidência os projetos de pesquisa realizados, principalmente aqueles em conjunto com as empresas.

Como fatores facilitadores, a empresa Basf The Chemical Company salienta que a cultura organizacional da empresa facilita relacionamentos com as universidades, pois a empresa realmente demonstra seus interesses, procura sempre buscar um relacionamento positivo e cria, como interesses, a difusão de tecnologia aliada à busca da inovação e sustentabilidade.

\section{CONSIDERACÕES FINAIS}

A relação Universidade-Empresa é um assunto tratado no contexto nacional e internacional, e esse contexto é pesquisado em sua maioria por meio de estudos de caso que procuram identificar características específicas de cada relação. Em virtude do contexto peculiar, este artigo enfocou o estudo da relação Universidade-Empresa sob a ótica da criação e transferência do conhecimento, procurando demonstrar como esse processo vem ocorrendo.

Foi possível evidenciar que os interesses da universidade e os interesses da empresa são semelhantes sob a ótica de criação e transferência do conhecimento, os mecanismos utilizados por ambas as organizações são semelhantes. 0 fato de a empresa estar instalada dentro da universidade também reflete na evolução e incremento de ações e atividades de interação, ressaltando o aperfeiçoamento e profissionalização de professores e acadêmicos envolvidos.

A criação do conhecimento organizacional, tanto na universidade quanto na empresa, é diferenciada em virtude do tempo de criação; enquanto a universidade pode aguardar pelas respostas, a empresa as procura fazendo assim o seu processo mais rápido. Contudo, os interesses institucionais das duas organizações se opõem em razão de suas finalidades que visam ao alcance de metas organizacionais e de respeito aos valores da organização.

A aproximação do conhecimento científico, conforme compreensão dos fatores citados pela universidade e pela empresa, permite para a empresa uma alavancagem tecnológica e a possibilidade de obtenção de vantagem competitiva diante de seus concorrentes. Já para a universidade, o fato do reconhecimento da empresa em estar adquirindo esse conhecimento científico, que causa uma credibilidade pela sua capacidade técnica, é percebido como fator de cumprimento de sua missão institucional.

Em relação às barreiras identificadas, os entrevistados da universidade percebem que a burocracia da 
universidade é um limitador e, por causa dessa burocracia, ocorre o preconceito construído pela comunidade universitária acerca das parcerias com as empresas - ainda muitos se protegem com os direitos e deveres regidos pela burocracia, causando, assim, engessamento das relações.

Ao analisar os aspectos facilitadores na relação Universidade-Empresa, os entrevistados da universidade ressaltam que é necessário possuir contatos e realizar o marketing do grupo de pesquisa, divulgando, desse modo, trabalhos já realizados e em andamento. Para a empresa, o fator facilitador parte da cultura organizacional, estimulando o surgimento de parcerias com as universidades, principalmente parcerias voltadas à difusão de tecnologia e desenvolvimento de produtos, especialmente projetos que visam à busca pela inovação e sustentabilidade.

Algumas sugestões podem ser feitas para a UEPG, tendo em vista a melhoria de suas relações com as empresas. A primeira seria, pelo grande número de delegações internacionais que visitam a instituição, a inserção de empresas, o que a tornaria mais produtiva. Isso ajudaria na recepção de comitivas reduzindo seu impacto na rotina da organização e, ainda, aumentando a imagem institucional da universidade e das empresas envolvidas, pois reforçaria a visão estrangeira dessas instituições como participantes da rede de desenvolvimento de pesquisas existentes no país.

Outra sugestão seria a utilização das redes de contatos já existentes na universidade para elevação da inserção internacional da relação produtiva que possui com a empresa Basf the Chemical Company. Desse modo, poderiam surgir novas relações com universidades internacionais, assim como cursos e trabalhos conjuntos visando ao enfoque da agricultura.

No que se refere às vitrines tecnológicas, é necessária uma iniciativa por parte da Fazenda-Escola em cobrar a realização desse tipo de evento que está desativado. Essas vitrines ajudam a disseminação do conhecimento, tanto para a sociedade interessada quanto para os acadêmicos e professores presentes dos cursos das ciências agrárias.

Além disso, a universidade precisa promover um ambiente adequado para que a expectativa do pesquisador possa ser atendida em relação ao desenvolvimento de pesquisa, pois infelizmente hoje está desamparado pela instituição, principalmente no que se refere à estrutura física, humana e financeira.

Para a universidade facilitar o processo de cooperação, é necessário diminuir a burocracia existente, a fim de que os excessos de encargos burocráticos não atrasem o desenvolvimento de pesquisas conjuntas. Com isso, estimulem reuniões e discussões entre os profissionais da iniciativa privada e das universidades, sobre o assunto relação universidade-empresa, tanto para aumentar as possibilidades de futuras integrações como para se conhecer melhor o que está em desenvolvimento nos diferentes centros.

Apesar das limitações apresentadas, este estudo procurou contribuir para o entendimento das parcerias interorganizacionais para a criação e transferência do conhecimento entre organizações de natureza distinta e também buscou um foco diferenciado em que o produto principal é o conhecimento.

\section{INNOVATION AS A CONNECTION TO DEVELOP UNIVERSITY- COMPANY PARTNERSHIPS}

\section{ABSTRACT}

The present study is a case study in the agricultural sector. It aims to analyze the relationship between university-industry in what concerns the creation and transfer of knowledge. We intend to analyze this type of relationship as it occurs in the Experimental Farm Station - called School Farm, which belongs to the State University of Ponta Grossa, and is located in an Advanced Experimental Campus under the responsibility of the company BASF S/A. The university-company relationship has developed and, within this context, educational institutions and research can contribute effectively to the development of new technologies and knowledge, representing an alternative for innovation along with the private sector. In this sense, forms, intervening structural factors within the creation and transfer of knowledge were identified through interviews with the university researcher, the school farm manager and the technician responsible for the experimental field of the company. We chose therefore a qualitative research based on case study to explore the perceptions of the people involved in the the phenomenon being analyzed. The results indicate new factors which interfere in the process of creation and transfer of knowledge and which are important for the management of the process and for the relationship with the company.

Keywords: Knowledge. University-industry relationship. Innovation. 


\section{REFERÊNCIAS}

ALMEIDA, M. . The evolution of the incubator movement in Brazil. International Journal of Technology and Globalisation (Print), v. 1, p. 258-277, 2005.

ALVARENGA NETO, Rivadávia C. D. A construção do conceito de gestão do conhecimento: práticas organizacionais, garantias literárias e o fenômeno social. Reuna, Belo Horizonte, v. 9, n. 2, p. 57-74, ago. 2004.

AUDY, J. L. N.; MOROSINI, M. C. (Org.). Entre a tradição e a renovação: os desafios da universidade empreendedora. Porto Alegre: EDIPUCRS, 2006.

BALESTRIN, Alsones; VERSCHOORE, Jorge. Redes de Cooperação Empresarial: estratégias de gestão na nova economia. Porto Alegre: Bookman, 2008.

BASF. História. Disponível em: <http://www.basf.com.br/sac/web/brazil/pt_BR/sobre-a-basf/historia>. Acesso em: 11 jun. 2014.

BETZ, F. et al. O fator tecnológico: a velocidade das inovações tecnológicas demanda um novo modelo de gerenciamento. HSM Management, São Paulo, v. 1, n. 1, p. 106-110, mar./abr. 1997.

CHAIMOVICH, H. Por uma relação mutuamente proveitosa entre universidade de pesquisa e empresas. Revista de Administração, São Paulo, v. 34, n. 4, p. 18-22, out./dez. 1999.

CLOSS, L.; FERREIRA, G. Transferência de tecnologia Universidade-Empresa: uma revisão das publicações científicas brasileiras no período de 2005-2009. In: Encontro Nacional da Associação Nacional de Pósgraduação e Pesquisa em Administração, 34., 2010, Rio de Janeiro. Anais... Rio de Janeiro: ANPAD, 2010.

COSTA, V. M. G.; CUNHA, J. C. A universidade e a capacitação tecnológica das empresas. Revista de Administração Contemporânea, Curitiba, v. 5, n. 1, p. 61-81, 2001.

DAGNINO, R. A relação Universidade-Empresa no Brasil e o argumento da Hélice Tripla. Convergencía (Toluca), México, v. 11, n. 35, p. 253-291, 2004.

DYER, W. Jeffrey; KALE, Prashant. Relational capabilities: drivers and implications. In: HELFAT, Constance et al. (Org.). Dynamic Capabilities: understanding strategic change in organizations . UK: Blackwell Publishing, 2007. p. 65-79.

DRUCKER, P. F. As fronteiras da administração: onde as decisões do amanhã estão sendo determinadas hoje. São Paulo: Pioneira, 1989.

ETZKOWITZ, H. Researchgroups as "quasi-firms": the invention of the entrepreneurial university. Research Policy, New York, v. 32, n. 1, p. 109-121, 2003.

ETZKOWITZ, H. Hélice tríplice: metáfora dos anos 90 descreve bem o mais sustentável modelo de sistema de inovação. Revista Conhecimento e Inovação, Campinas, v. 6, n. 1, p. 6-9, 2010.

ETZKOWITZ, H.; LEYDESDORFF, L. The dynamics of innovation: from National Systems and "Mode 2" to a Triple Helix of university-industry-government relations. ResearchPolicy, New York, v. 29, n. 2, p. 109-123, 2000.

FISCHMANN, A. A.; CUNHA, N. C. V. Alternativas de ações estratégicas para promover a interação Universidade-Empresa através dos escritórios de transferência de tecnologia. In: SEMINÁRIO LATINOIBEROAMERICANO DE GESTÍON TECNOLÓGICA, 10., 2003, Cidade do México. Anales... Cidade do México: ALTEC, 2003. v. 1.

FONSECA, R. Inovação tecnológica e o papel do governo. Revista Parcerias Estratégicas, Brasília, n. 13, p. 64-69, dez. 2001. 
GONÇALO, C. R. Inteligência organizacional: do debate metafísico para uma perspectiva contextual em estratégias de conhecimento. In: Encontro da Associação Nacional dos Programas de Pós-graduação em Administração, 29., 2005, Brasília. Anais... Brasília: ANPAD, 2005.

GONÇALO, C. R.; ZANLUCHI, J. Relacionamento entre empresa e universidade: uma análise das características de cooperação em um setor intensivo em conhecimento. Revista de Administração e Contabilidade da Unisinos, São Leopoldo, v. 8, n. 3, p. 261-272, jul./set. 2011.

GRYNSZPAN, F. A visão empresarial da cooperação com a universidade. Revista de Administração, São Paulo, v. 34, n. 4, p. 23-31, out./dez. 1999.

HAUKNES, Johan. Services in innovation: innovation in services. Oslo: STEP group, 1998.

HENDERSON, R. M.; CLARK, B. K. Architectural innovation: the reconfiguration of existingproduct technologies and the failure of established firms. Administrative Science Quarterly, Michigan, v. 35, n. 1, p. 9-30, 1990.

INSTITUTO BRASILEIRO DE GEOGRAFIA E ESTATÍSTICA (IBGE). Dados Brasil: 2011 - IBGE. [2011]. Disponível em:

<http://www.pintec.ibge.gov.br/index.php?option=com_content\&view=article\&id=45\&Itemid=12>. Acesso em: 11 maio 2014

KOGUT, B.; ZANDER, U. Knowledge of the firm, combinative capabilities, and the replication of technology. Organization Science, Catonsville, MD, USA, v. 3, n. 3, p. 383-397, 1992.

LEONARD-BARTON, D. Nascentes do saber: criando e sustentando as fontes de inovação. Rio de Janeiro: FGV, 1998.

LEYDESDORFF, L. The triple helix of university-industry-government relations. In: CARAYANNIS, E.; CAMPBELL, D. (Eds.). Encyclopedia of creativity, innovation, and entrepreneurship. New York: Springer, 2012. p. 1-17.

LUCCHESSI, M. A. S. Universidade no limiar do terceiro milênio: desafios e tendências. Santos: Leopoldianum, 2002.

MATTOS, J. R. L. de; GUIMARÃES, L. dos S. Gestão tecnologia e inovação: uma abordagem prática. São Paulo: Saraiva, 2005.

MENESES, P. Universidade e sociedade. Revista de Filosofia, Belo Horizonte, v. 27, n. 87, p. 5-15, 2000.

MOREIRA, D. A.; QUEIROZ, A. C. Inovação tecnológica e organizacional. São Paulo: Thomson Learning, 2007.

NONAKA, I. The knowledge-creating company. Harvard Business Review, Boston, USA, n. 69, p. 96-104, Nov./Dec. 1991.

NONAKA, I.; TAKEUCHI, H. Criação do conhecimento na empresa. 14. ed. Rio de Janeiro: Campus, 1997.

NOVELI, M.; SEGATTO, A. P. Processo de cooperação Universidade-Empresa para a inovação tecnológica em um parque tecnológico: evidências empíricas e proposição de um modelo conceitual. Revista de Administração e Inovação, São Paulo, v. 9, n. 1, p. 81-105, jan./mar. 2012.

NOVO, L. F; MELO, P. A. Universidade empreendedora: fortalecendo os caminhos para a responsabilidade social. In: COLÓQUIO INTERNACIONAL SOBRE GESTÃO UNIVERSITÁRIA NAS AMÉRICAS, 3., 2003. Anais... Buenos Aires: UNTREF, 2003. Disponível em: <http://www.inpeau.ufsc.br/coloquio03/autor.htm>. Acesso em: 11 jul. 2013. 
ORGANIZAÇ̃̃O PARA COOPERAÇ̃̃O ECONÔMICA E DESENVOLVIMENTO (OCDE). Manual de Oslo: diretrizes para coleta e interpretação de dados sobre inovação. 3. ed. [S.I.]: OCDE, 2005.

PLONSKI, G. A. Cooperação empresa-universidade na Ibero-América: estágio atual e perspectivas. Revista de Administração, São Paulo, v. 30, n. 2, p. 65-74, abr./jun. 1995.

PLONSKI, G. A. Cooperação Universidade-Empresa: um desafio gerencial complexo. Revista de Administração, São Paulo, v. 34, n. 4, p. 5-12, out./dez. 1999.

PORTO, G. S. A decisão empresarial de desenvolvimento tecnológico por meio da cooperação Universidade-Empresa. 2000. Tese (Doutorado em Administração) - Faculdade de Economia, Administração e Contabilidade, Universidade de São Paulo, São Paulo, 2000.

RESENDE, F.; TAFNER, P. (Org.). Brasil: o estado de uma nação. Brasília: IPEA, 2005.

SBRAGIA, R. et al. Inovação: como vencer esse desafio empresarial. São Paulo: Clio Editora, 2006.

SCHUMPETER, J. A. The theory of economic development. Nova York: Oxford University, 1961.

SEGATTO, A. P. Análise do processo de cooperação tecnológica Universidade-Empresa: um estudo exploratório. 1996. Dissertação (Mestrado em Administração) - Faculdade de Economia, Administração e Contabilidade, Universidade de São Paulo, São Paulo, 1996.

SILVA, S. Gestão do conhecimento: uma revisão crítica orientada pela abordagem da criação do conhecimento. Ciência da Informação, Brasília, v. 33, n. 2, p. 143-151, maio/ago. 2004.

SZULANSKI, G. Exploring internal stickiness: impediments to transfer of best practice within the firm. Strategic Management Journal, Malden, v. 17, p. 27-43, Winter Special Issue 1996.

SZULANSKI, G. The process of knowledge transfer: a diachronic analysis of stickness. Organizational Behavior and Human Decision Processes, Washington, v. 82, n. 1, p. 9-27, May, 2000.

WINTER, S. Understanding dynamic capabilities. Strategic Management Journal, Malden, v. 24, p. 991995, 2003.

ZANLUCHI. J. B. Relação Universidade-Empresa: um estudo no setor de T.I. do Estado do Rio Grande do Sul. 2008. Dissertação (Mestrado em Administração) - Universidade do Vale do Rio dos Sinos, São Leopoldo, 2008.

YIN, R. K. Case study research: design and methods: Sage Publications, 2001.

SUN TZU. A arte da guerra. Porto Alegre: L \& PM, 2008.

TARAPANOFF, K. (Org.). Inteligência organizacional e competitiva. Brasília: UNB, 2001.

TOMBS, G. What are the "best practices" in using internal organizational sources for competitive intelligence? In: FLEISHER, C. S.; BLENKHORN, D. L. (Org.). Controversies in competitive intelligence: the enduring issues. Westport: Praeger, 2003. p. 98-109.

VALENTIM, M. L. P. (Org.). Atuação do profissional na área da informação. São Paulo: Polis, 2004.

VALENTIM, M. L. P. et al. O processo de inteligência competitiva em organizações. DataGramaZero, v.4, n.3, jun. 2003. Disponível em: <http://www.dgz.org.br/jun03/Art_03.htm>. Acesso em: 16 jun. 2014. 
APÊNDICE A - Relação da fundamentação teórica com a elaboração do Roteiro de entrevista

\begin{tabular}{|c|c|c|}
\hline Dimensão & Categorias & Questões \\
\hline \multirow[t]{2}{*}{ Fatores estruturais } & Mecanismo de gestão & $\begin{array}{l}\text { 1) Como a universidade estimula o surgimento de relações com } \\
\text { a empresa, que visam à criação e transferência de conhecimen- } \\
\text { to? } \\
\text { 2) Quais são os possíveis processos informais dentro dessa } \\
\text { relação? } \\
\text { 3) Existe uma política de seleção dos pesquisadores que atuam } \\
\text { em parceria com a empresa? } \\
\text { 4) Que tipos de pesquisas são realizadas por meio de pesquisas } \\
\text { cooperativas com a empresa? } \\
\text { 5) De quem é a decisãa de com quem cooperar? } \\
\text { 6) De quem foi a iniciativa de implementação do campo } \\
\text { experimental? }\end{array}$ \\
\hline & Localização interna & $\begin{array}{l}\text { 1) Quais são as vantagens para a universidade em ter um campo } \\
\text { experimental de responsabilidade da empresa dentro de sua } \\
\text { propriedade? } \\
\text { 2) Quais são as possíveis desvantagens? } \\
\text { 3) Existem atividades em que a universidade utiliza as depen- } \\
\text { dências deste campo experimental? Evice-versa }\end{array}$ \\
\hline \multirow[t]{2}{*}{$\begin{array}{c}\text { Criação e transferência do conhecimento } \\
\text { organizacional }\end{array}$} & $\begin{array}{l}\text { Criação do conhecimento } \\
\text { Compartilhamento do conhecimento tácito. } \\
\text { Criação de conceitos. } \\
\text { Justificativa de conceitos. } \\
\text { Construção de um arquétipo. } \\
\text { Difusão interativa do conhecimento. }\end{array}$ & $\begin{array}{l}\text { 1) Como funcionam, e se existem, reuniões onde os indivíduos } \\
\text { compartilham experiências pessoais? } \\
\text { 2) Quais são as formas utilizadas pela universidade de repensar } \\
\text { os conceitos existentes? } \\
\text { 3) Quais fatores a universidade entende como essenciais para o } \\
\text { surgimento do novo conceito? } \\
\text { 4) Existem novos conceitos criados pela universidade que } \\
\text { acabam tornando-se algo tangível ou concreto? } \\
\text { 5) Como a universidade pode desenvolver novos conhecimentos, } \\
\text { partindo dessa suposta inovação tecnológica? }\end{array}$ \\
\hline & $\begin{array}{l}\text { Transferência do conhecimento } \\
\text { Iniciação. } \\
\text { Implementação. } \\
\text { Adaptação. } \\
\text { Integração. }\end{array}$ & $\begin{array}{l}\text { 1) Como é selecionado o conhecimento que será transferido, e } \\
\text { de quem é a decisão? } \\
\text { 2) Como é implementado esse conhecimento transferido? } \\
\text { 3) Depois de implementado o novo conhecimento, como a } \\
\text { universidade acompanha esse processo de adaptação? } \\
\text { 4) Como é avaliado esse novo conhecimento? }\end{array}$ \\
\hline \multirow[t]{2}{*}{ Fatores intervenientes } & Barreiras & $\begin{array}{l}\text { Quais são, e se existem, as barreiras para a relação U-E? Como } \\
\text { ultrapassá-las? }\end{array}$ \\
\hline & Facilitadores & Que fatores facilitam a relação Universidade-Empresa? \\
\hline
\end{tabular}

